\title{
A Study on Effect of Servant Leadership and Perceived Organizational Support on Characteristics of Agile Organizational Culture
}

\author{
Tae-Wan Kim ${ }^{1}$, Yen-Yoo You ${ }^{2} \&$ Jung-Wan Hong ${ }^{2}$ \\ ${ }^{1}$ Dept. of Knowledge Service \& Consulting, Hansung University, Seoul, South Korea \\ ${ }^{2}$ Division of Smart Management Engineering, Hansung University, Seoul, South Korea \\ Correspondence: Yen-Yoo You, Professor, Division of Smart Management Engineering, Hansung University, Seoul, \\ South Korea. Tel: 82-10-5201-7743. E-mail: threey0818@ hansung.ac.kr
}

Received: April 9, 2020

Accepted: May 9, 2020

Online Published: May 23, 2020

doi:10.5430/rwe.v11n2p1

URL: https://doi.org/10.5430/rwe.v11n2p1

\begin{abstract}
Background/Objectives: The purpose of this study was to identify factors of leadership and organizational support that have effect on establishing the characteristics of agile organizational culture adopted recently by many organizations as a way to deal with rapidly changing market.

Methods/Statistical analysis: A research model was developed, based on previous studies, by selecting Empowerment, Use of Collective Intelligence, and Continuous Learning, selected as Characteristics of Agile Organizational Culture, and Servant Leadership and Perceived Organizational Support (POS) as the influencing variables. The relationships among variables were identified using regression analysis and mediating effect analysis. The subjects were workers working at headquarters of the National Agricultural Cooperative Federation and the Agribusiness Group. The questionnaire survey was conducted for about one month from Jan., 2020 and a total of 157 valid samples were obtained. SPSS (Ver. 22.0) was used in statistical analysis.

Findings: The results showed that the Servant Leadership has statistically significant effect on Empowerment and Use of Collective Intelligence but not on Continuous Learning which are Characteristics of Agile Organizational Culture. The Perceived Organizational Support (POS) has statistically significant effect on all of the Characteristics of Agile Organizational Culture: Empowerment, Use of Collective Intelligence, and Continuous Learning. The results of mediating effect analysis showed that POS partially mediated the effect of Servant Leadership on Empowerment and Use of Collective Intelligence and fully mediated the effect on Continuous Learning. The results suggested that, for the establishment of agile culture in an organization, it is very important to exercise Servant Leadership, which is a leadership that maximize the potential of the members of the organization based on the spirit of human respect, and to give to members the perception of the full support and rewards provided by organization.

Improvements/Applications: This study was conducted for employees working at a specific organization therefore it is difficult to generalize the results to overall industries and organizations. In the future, it is necessary to expand sample population and to conduct comparative studies between groups that have introduced agile organizational culture and ones that does not. It is also recommended to conduct additional studies on the factors of leadership and organizational support that have effect on the characteristics of agile organizational culture.
\end{abstract}

Keywords: servant leadership, perceived organizational support, characteristics of agile organizational culture, empowerment, use of collective intelligence, continuous learning

\section{Introduction}

The recent rapid progress of the 4th Industrial Revolution or digital transformation is gradually shortening the business cycle and product life cycle. This indicates that the time for companies to maintain the differentiated competitive advantage they have achieved is becoming shorter and also that it is becoming very difficult to predict and adapt to changes in an industry, market or business environment. This change in the environment has led to a number of cases where market leaders such as Motorola, Sony, and Kodak that once unrivaled in their own power have collapsed by new chasers. Many Korean companies, in response to this change in market, have invested heavily in management and organizational culture that can deal with the rapid market changes. In particular, agile method, organization, and cultures derived from software development methods have been actively introduced. The purpose of this study was, 
considering that the leadership is one of the most important factors in forming an organizational culture, to provide implications for many companies planning to build an agile organizational culture in the future by identifying various influence relations among servant leadership, which has democratic and human-centered characteristics, perceived organizational support, and characteristics of agile organizational culture.

\section{Materials and Methods}

\subsection{Theoretical Background}

\subsubsection{Servant Leadership}

The servant leadership was presented for the first time by Greenleaf (1970) in his book The servant as Leader (Greenleaf, 1970). The servant leadership is one that gives priority to the interests of the members of the organization rather than the leader's own concern and enables the members of the organization to reach their full potential based on the spirit of respect for human and thus is important for the survival and development of today's enterprise (Choi, 2017). The concept of servant leadership is rather comprehensive therefore many scholars have suggested various sub-concepts. Spears (1995) presented ten virtues as leadership based on democratic principles: persuasion, listening, commitment to growth, empathy, healing, awareness, foresight, stewardship, community building, and conceptualization (Spears, 1995). The persuasion is based on open dialogue, not control or command, listening emphasizes the importance of communication between leaders and subordinates, and commitment to growth means that leaders should always help the members of the organization to grow. Dierendonck (2011) categorized servant leadership into six virtues: empowering and developing people, providing direction, interpersonal acceptance, humility, authenticity, and stewardship. 'Empowering and developing people' is empowering subordinates, while believing in and emphasizing subordinates' competencies and giving them a right to make their own decision by developing such competencies (Dierendonck, 2011). Lee (2019), after reviewing many previous studies, categorized servant leadership as building community, conceptualization, and commitment to the growth. 'Building community' is explained as a leadership, unlike traditional one that prevents members of the organization from expressing their opinions and ideas, that builds and enhances the value of relationships between members by inducing communication, voluntary participation, and cooperation in the process of achieving the goals (Lee, 2019).

\subsubsection{Perceived Organizational Support}

Perceived organizational support (POS), a concept based on social exchange theory, was established as a theory by Eisenberger et al. (1990) and describes the extent to which an organization is immersed in its members (Eisenberger and Peter, 1990). POS is similar to organizational commitment in that it is an individual's attitude toward the organization, but organizational commitment is a members' commitment to the organization while the organizational commitment is, on the contrary, an organization's commitment to their members (Park, 2017). POS, personifying the organization, describes that the perceived level of the support of a member increase when he/she receives praise, encouragement, and recognition, leading to enhancement of organizational commitment, which has a positive effect on the organization's performance (Jin and Kim, 2016). POS enhances the relationships among the members of the organization by increasing their self-recognition and self-esteem and facilitating the communication and cooperation among them (Organ et al., 1990). The members whose POS is high contribute voluntarily and autonomously to the achievement of organization's goals and act on behalf of benefit of the organization (Rhoades and Eisenberger, 2002). POS is also closely related to the individual attitudes and behaviors in an organization, and these relations affects the attitudes of members to propose and implement creative ideas on their own, which contributes to organizational performance by increasing their job satisfaction and organizational commitment (Kim, 2018). The members who recognize that the organization's support and consideration is sufficient during their learning, in addition, are likely to achieve higher performance in learning and build more excellent learning organization, resulting in facilitation of learning in the organization (Jeong and Lee, 2017).

\subsubsection{Characteristics of Agile Organizational Culture}

The agility, a concept that was used as the organization's adaptivity in the 1950s, emerged as a response to rapid change and a dynamic environment in the early 1990s. In the 2000s, the adjective 'Agile' was first used in software development field (AN et al., 2019). In February 2001, 17 prominent software developers including Kent Beck, after a lengthy discussion to share their experiences and explore ways to work on better software projects at Snowbird Ski Resort, Utah, USA, announced Agile Manifesto and the derived method was named 'Agile'. Agile, which coined in software development theory, has recently been adopted by many organizations as an important concept for detecting enterprise's environmental dynamics, threats and opportunities. Agile organizations refer ones that adopt this Agile methodology and possess agile capacity to respond to market changes quickly and effectively by promoting 
adaptability and flexibility (Siakas and Siakas, 2007). Agile culture has not yet been defined as a concept, and the characteristics of agile organizations have been defined focusing on the factors by many scholars. Agile culture is a characteristic of a horizontal organization with flexibility and spontaneity where members actively participate, and cooperation, participation, delegation, agreement and compromise has been proposed as important characteristics of the culture (Harraf, et al. 2015). Harraf et al. (2015) studied the elements of organizational agility and claimed that this includes ten pillars represented by Empowerment, Tolerance for Ambiguity, Structural Fluidity, Culture of Innovation, Vision, Communication, Change Management, Market Analysis and Response, Operations Management, and Development of a Learning Organization (Harraf, et al. 2015). In addition, Gren Lucas, Richard Torkar, and Robert Feldt (2016) indicated that agile culture has characteristics such as continuous learning and improvement, support and collaboration, team orientation, empowerment, support for informal communication, knowledge sharing, and change orientation (Gren et al., 2015). Jeong (2019) proposed autonomic structure, collective intelligence, innovation culture, and immersive talent management as the main characteristics of agile organizations (Jeong, 2019).

\subsection{Proposed Work}

\subsubsection{Research Model}

This study, based on the previous studies, developed the research model as shown in Fig. 1 by adopting Servant Leadership, which is a leadership that leads the organization's potential to the fullest based on democratic principles, and POS, meaning organizational commitment to members, as independent variables, Empowerment, Use of Collective Intelligence, and Continuous Learning as characteristics of organizational culture as dependent variables, and POS as a parameter to mediate causal relationship between Servant Leadership and Characteristics of Agile Organizational Culture (Hung and Trinh, 2019); (Irshad, 2017).

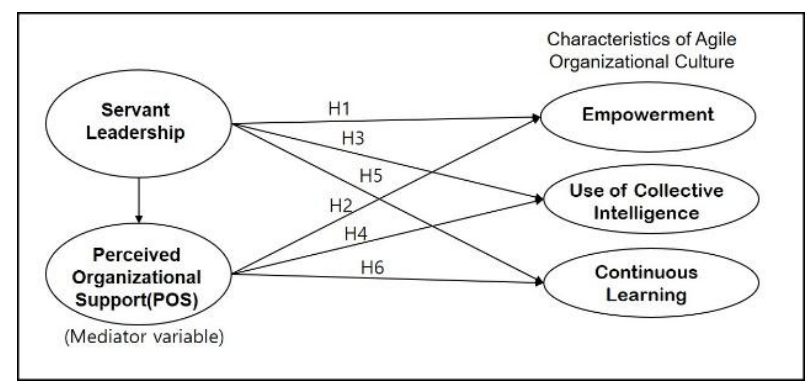

Figure 1. Research model

\subsubsection{Research Hypotheses}

Various previous studies on the relationship among Servant Leadership, POS, and Characteristics of Agile Organizational Culture have been reviewed as described above and Empowerment, Use of Collective Intelligence, and Continuous Learning as a central Characteristics of Agile Organizational Culture have been adopted on which two independent variables are expected to have effect, and the following hypotheses were proposed:

H1: Servant Leadership will positively affect Empowerment

H2: Perceived Organizational Support will positively affect Empowerment

H3: Servant Leadership will positively affect Use of Collective Intelligence

H4: Perceived Organizational Support will positively affect Use of Collective Intelligence

H5: Servant Leadership will positively affect Continuous Learning

H6: Perceived Organizational Support will positively affect Continuous Learning

H7: Perceived Organizational Support will have significant mediating effect on the relationship between

Servant Leadership and Empowerment

H8: Perceived Organizational Support will have significant mediating effect on the relationship between

Servant Leadership and Use of Collective Intelligence 
H9: Perceived Organizational Support will have significant mediating effect on the relationship between

Servant Leadership and Continuous Learning

\subsection{Research Methods}

\subsubsection{Population and Sample Selection}

The subjects of this study were workers from employees to general managers working at headquarters of the National Agricultural Cooperative Federation and Agribusiness Group in Korea, which has been committed to building horizontal and flexible organizational culture and introducing agile organization and culture since 2018. The reason for choosing workers of headquarter in sample survey was to increase the significance of the response by selecting a group with an excellent understanding of agile culture in the early stages of introducing the culture. The questionnaire survey was conducted for about one month from Jan., 2020 and a total of 157 valid samples were obtained. SPSS (Ver. 22.0) was used in statistical analysis.

\subsubsection{Measurement and Operational Definition of Variables}

The measurement tool was composed based on several previous studies and operational definitions of variables were developed as shown in Table 1.

Table 1. Operational definition of variables

\begin{tabular}{|c|c|c|}
\hline Variable & Operational Definition & Ref. \\
\hline $\begin{array}{c}\text { Servant } \\
\text { Leadership }\end{array}$ & $\begin{array}{l}\text { The degree to which the leader does his best to help his } \\
\text { subordinates, solves his difficulties, uses wisdom to predict the } \\
\text { situation, and provides sufficient explanation and persuasion for } \\
\text { understanding }\end{array}$ & $\begin{array}{c}\text { Lee } \\
(2019) \\
\mathrm{Yu} \\
(2019)\end{array}$ \\
\hline $\begin{array}{l}\text { Perceived } \\
\text { Organizational } \\
\text { Support }\end{array}$ & $\begin{array}{l}\text { The degree to which an organization values the members' } \\
\text { achievements, goals, and values, tries to grow them, is always } \\
\text { concerned for them, actively helps them when problems arise, and } \\
\text { is proud of their achievements }\end{array}$ & $\begin{array}{c}\text { Park } \\
(2019)\end{array}$ \\
\hline Empowerment & $\begin{array}{l}\text { The degree to which members of an organization have } \\
\text { independence and autonomy in their work, make decisions on their } \\
\text { own, and exercise influence and control over their work }\end{array}$ & $\begin{array}{c}\text { Kim } \\
(2019) \\
\operatorname{Kim} \\
(2019)\end{array}$ \\
\hline $\begin{array}{l}\text { Use of } \\
\text { Collective } \\
\text { Intelligence }\end{array}$ & $\begin{array}{l}\text { The degree to which members works together with their peers, are } \\
\text { delighted to work with them, know each other's abilities, and share } \\
\text { their personal insights or learning outcomes with them. }\end{array}$ & $\begin{array}{l}\text { Cho } \\
(2017) \\
\text { Kim } \\
(2015)\end{array}$ \\
\hline $\begin{array}{l}\text { Continuous } \\
\text { Learning }\end{array}$ & $\begin{array}{l}\text { The degree to which one continues to participate in in-house } \\
\text { education, external education, club activity, study groups to } \\
\text { develop one's careers, seeks advice on work, and refer to related } \\
\text { materials to know exactly one's own strength and weakness. }\end{array}$ & $\begin{array}{c}\text { Song } \\
\text { (2018) }\end{array}$ \\
\hline
\end{tabular}

\section{Results and Discussion}

\subsection{Validity and Reliability Analysis}

This study first conducted validity analysis on the factors that constitute servant leadership, POS, and characteristics of agile organizational culture. The exploratory factor analysis was performed to verify the validity in which principal component analysis was performed to extract the constituent factors and Varimax orthogonal rotation was used to differentiate factors clearly. The results showed that the data is suitable for factor analysis as evidenced by $\mathrm{KMO}$ of .866 , higher than normal value .8 , and $\chi 2(\mathrm{p})$ of .000 in Bartlett sphericity test. In addition, the accumulation variance $\%$, a value of rotation sums of squared loadings, exceeded the general level of $60 \%$, reaching $64.3 \%$, indicating that five factors fully explain the total variance of the measured variables. In the rotated component using the Varimax rotation method, the loading value of each factor in the matrix was higher than .5 , confirming the 
convergent validity, and the communality was higher than general standard, .4 , suggesting no problem in using this data. Reliability analysis results confirmed the reliability in that all Cronbach's alpha coefficients exceeded .6, a general standard. The Cronbach's alphas coefficients when each factor was removed were less than that for the corresponding variable except for POS4, indicating that no measurement variable should be removed. POS4 was not removed because the Cronbach's alpha coefficient of the POS variable was very high, .904 , indicating sufficient reliability. The validity and reliability analysis results are shown in Table 2.

Table 2. Exploratory factor analysis and reliability test

\begin{tabular}{|c|c|c|c|c|c|c|c|c|}
\hline & \multicolumn{5}{|c|}{ Factors } & \multirow{2}{*}{$\mathrm{CM}$} & \multirow{2}{*}{$\begin{array}{l}\mathrm{C} \alpha \\
-\mathrm{D}\end{array}$} & \multirow{2}{*}{$\mathrm{C} \alpha$} \\
\hline & 1 & 2 & 3 & 4 & 5 & & & \\
\hline SL4 & .880 & & & & & .824 & .916 & \multirow{8}{*}{.932} \\
\hline SL5 & .834 & & & & & .730 & .922 & \\
\hline SL3 & .829 & & & & & .707 & .922 & \\
\hline SL8 & .824 & & & & & .739 & .920 & \\
\hline SL6 & .788 & & & & & .646 & .927 & \\
\hline SL2 & .750 & & & & & .635 & .927 & \\
\hline SL7 & .736 & & & & & .643 & .927 & \\
\hline SL1 & .736 & & & & & .674 & .926 & \\
\hline POS2 & & .868 & & & & .824 & .873 & \multirow{6}{*}{.904} \\
\hline POS3 & & .856 & & & & .781 & .875 & \\
\hline POS5 & & .801 & & & & .733 & .883 & \\
\hline POS6 & & .796 & & & & .739 & .878 & \\
\hline POS4 & & 609 & & & & .492 & .905 & \\
\hline POS1 & & .584 & & & & .561 & .902 & \\
\hline EMP6 & & & .794 & & & .698 & .835 & \multirow{6}{*}{.866} \\
\hline EMP5 & & & .781 & & & .665 & .833 & \\
\hline EMP2 & & & .735 & & & .625 & .845 & \\
\hline EMP4 & & & .721 & & & .625 & .847 & \\
\hline EMP3 & & & .715 & & & .634 & .842 & \\
\hline EMP1 & & & .616 & & & .508 & .856 & \\
\hline CL2 & & & & .814 & & .703 & .750 & \multirow{6}{*}{.807} \\
\hline CL1 & & & & .810 & & .705 & .755 & \\
\hline CL3 & & & & .731 & & .595 & .774 & \\
\hline CL4 & & & & .657 & & .507 & .779 & \\
\hline CL6 & & & & .546 & & .484 & .794 & \\
\hline CL5 & & & & .498 & & .470 & .803 & \\
\hline UCI3 & & & & & .789 & .705 & .618 & \multirow{4}{*}{.716} \\
\hline UCI4 & & & & & .700 & .607 & .608 & \\
\hline UCI2 & & & & & .625 & .606 & .683 & \\
\hline UCI1 & & & & & .457 & .529 & .703 & \\
\hline EV & 5.804 & 4.172 & 3.865 & 3.367 & 2.089 & & & \\
\hline $\mathrm{V} \%$ & 19.345 & 13.906 & 12.883 & 11.223 & 6.964 & & & \\
\hline AV\% & 19.345 & 33.252 & 46.134 & 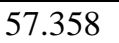 & 64.321 & & & \\
\hline
\end{tabular}

Ref) SL: Servant Leadership, POS: Perceived Organizational Support, EMP: Empowerment,

CL: Continuous Learning, UCI: Use of Collective Intelligence, EV: Eigen Value,

V\%: Variance\%, AV\%: Accumulation Variance\%, CM: Communality,

$\mathrm{C} \alpha-\mathrm{D}$ : Cronbach' $\alpha$ if item is deleted, $\mathrm{C} \alpha$ : Cronbach' $\alpha$ 


\subsection{Correlation Analysis}

Correlation analysis, a statistical technique that analyzes whether the relationship between two variables is independent or related, is performed to identify the directionality and multiple collinearity between variables, before regression analysis. The Pearson's correlation analysis was performed and the results showed that correlation coefficients were positive and statistically significant $(\mathrm{p}<.01)$, indicating that the regression analysis to analyze the causal relationship is feasible. The results are shown in Table 3.

Table 3. Correlation coefficient analysis

\begin{tabular}{cccccc}
\hline & SL & POS & CL & EMP & UCI \\
\hline SL & 1 & & & & \\
\hline POS & $.365^{* *}$ & 1 & & & \\
\hline CL & $.224^{* *}$ & $.384^{* *}$ & 1 & & \\
\hline EMP & $.313^{* *}$ & $.487^{* *}$ & $.231^{* *}$ & 1 & \\
\hline UCI & $.388^{* * *}$ & $.371^{* *}$ & $.410^{* *}$ & $.388^{* *}$ & 1 \\
\hline
\end{tabular}

**: The correlation is valid at .01 level

Ref) SL: Servant Leadership, POS: Perceived Organizational Support, CL: Continuous Learning,

EMP: Empowerment, UCI: Use of Collective Intelligence

\subsection{The Result of Hypothesis Testing}

\subsubsection{The Results of Multiple Regression Analysis}

Multiple regression analysis was performed to investigate the effects of servant leadership and POS on empowerment, use of collective intelligence, and continuous learning which are characteristics of agile organizational culture. The results of testing the relationship between servant leadership and POS on empowerment are shown in Table 4. All VIFs were less than 10, indicating no multicollinearity among the independent variables and the Durbin-Watson coefficient was 2.077, which is far from 0 and 4 and close to 2, confirming the independence of the residual term. These results showed that this data is fit for regression analysis. The coefficient table was reviewed to investigate whether the independent variable has a linear effect on the dependent variable, and the results showed statistically significant effect evidenced by $\mathrm{t}(\mathrm{p}) \mathrm{s}$ of .039 and .000 for servant leadership and POS, respectively. The non-standardized coefficients B for both were positive, meaning that the higher servant leadership and POS are associated with the higher empowerment, supporting $\mathrm{H} 1$ and $\mathrm{H} 2$. The standardization coefficients $\beta$ indicated that the influence of the POS (.431) on empowerment is much higher than that of servant leadership (.155). These results indicate that the efforts to increase POS are more important for the cultural characteristics of empowerment to be well implemented, though exercise of servant leadership is also important. $\mathrm{R}^{2}$ of .259 indicated that the independent variables, servant leadership and POS, accounted for $25.9 \%$ of the dependent variable, empowerment.

Table 4. Effect of servant leadership, perceived organizational support on empowerment

\begin{tabular}{ccccccc}
\hline & $\mathrm{B}$ & $\mathrm{SE}$ & $\beta$ & $\mathrm{t}$ & $\mathrm{P}$ & $\mathrm{VIF}$ \\
\hline (Constant) & 1.271 & .272 & & 4.669 & .000 & \\
\hline $\mathrm{SL}$ & .140 & .067 & .155 & 2.085 & .039 & 1.154 \\
\hline $\mathrm{POS}$ & .426 & .074 & .431 & 5.780 & .000 & 1.154 \\
\hline $\mathrm{F}=26.851(\mathrm{p}=.000), \mathrm{R}^{2}=.259$, adjusted & $\mathrm{R}^{2}=.249$, \\
Durbin-Watson's d =2.077
\end{tabular}

Dependent Variable: Empowerment

Ref) SL: Servant Leadership, POS: Perceived Organizational Support 
The effects of servant leadership and POS on the use of collective intelligence were tested and the results are shown in Table 5. All VIFs were less than 10, indicating no multicollinearity among the independent variables and the Durbin-Watson coefficient was 1.986, confirming the independence of the residual term. The coefficient table was reviewed to investigate whether the independent variable has a linear effect on the dependent variable, and the results showed statistically significant effect evidenced by $\mathrm{t}(\mathrm{p}) \mathrm{s}$ of .000 and .001 for servant leadership and POS, respectively. The non-standardized coefficients B for both were positive, meaning that the higher servant leadership and POS are associated with the higher use of collective intelligence, supporting $\mathrm{H} 3$ and $\mathrm{H} 4$. The standardization coefficients $\beta$ indicated that the influence of servant leadership (.291) on the use of collective intelligence is higher than that of POS (.265). $\mathrm{R}^{2}$ of .211 indicated that the independent variables, servant leadership and POS, accounted for $21.1 \%$ of the dependent variable, use of collective intelligence.

Table 5. Effect of servant leadership, perceived organizational support on use of collective intelligence

\begin{tabular}{crrrrrr}
\hline & $\mathrm{B}$ & $\mathrm{SE}$ & $\beta$ & $\mathrm{t}$ & $\mathrm{P}$ & $\mathrm{VIF}$ \\
\hline (Constant) & 2.401 & .220 & & 10.907 & .000 & \\
\hline $\mathrm{SL}$ & .206 & .054 & .291 & 3.785 & .000 & 1.154 \\
\hline POS & .205 & .060 & .265 & 3.443 & .001 & 1.154 \\
\hline \multicolumn{5}{c}{$\mathrm{F}=20.591(\mathrm{p}=.000), \mathrm{R}^{2}=.211$, adjusted } & $\mathrm{R}^{2}=.201$, \\
Durbin-Watson's d =1.986
\end{tabular}

Dependent Variable: Use of Collective Intelligence

Ref) SL: Servant Leadership, POS: Perceived Organizational Support

Lastly, the effects of servant leadership and POS on the use of continuous learning were tested and the results are shown in Table 6. All VIFs were less than 10, indicating no multicollinearity among the independent variables and the Durbin-Watson coefficient was 1.780, confirming the independence of the residual term. The significance of the regression coefficients were tested to identify a independent variable that has significant effect on dependent one and the results showed that the servant leadership has no significant effect $(\mathrm{t}(\mathrm{p})=.225)$ while POS has statistically significant one $(\mathrm{t}(\mathrm{p})=.000)$ and positive non-standardized coefficients $\mathrm{B}$, meaning that the higher POS is associated with the higher level of continuous learning, supporting H6, while H5 was rejected. $\mathrm{R}^{2}$ of .155 indicated that the independent variables, servant leadership and POS, accounted for $15.5 \%$ of the dependent variable, continuous learning.

Table 6. Effect of servant leadership, perceived organizational support on continuous learning

\begin{tabular}{ccccccc}
\hline & $\mathrm{B}$ & $\mathrm{SE}$ & $\beta$ & $\mathrm{t}$ & $\mathrm{P}$ & $\mathrm{VIF}$ \\
\hline (Constant) & 1.797 & .284 & & 6.337 & .000 & \\
\hline $\mathrm{SL}$ & .085 & .070 & .097 & 1.219 & .225 & 1.154 \\
\hline POS & .337 & .077 & .348 & 4.380 & .000 & 1.154 \\
\hline $\mathrm{F}=14.172(\mathrm{p}=.000), \mathrm{R}^{2}=.155$, adjusted & $\mathrm{R}^{2}=.144$, \\
Durbin-Watson's d $=1.780$ \\
\hline
\end{tabular}

Dependent Variable: Continuous Learning

Ref) SL: Servant Leadership, POS: Perceived Organizational Support

\subsubsection{The Results of Mediating Effect Test}

The three-step test proposed by Baron \& Kenny was used to investigate whether POS mediates the influence of servant leadership on characteristics of agile organizational culture. The mediating effect of POS on the relationship between servant leadership and empowerment was analyzed and the results are shown in Table 7. In the first step of mediating effect test, the servant leadership was shown to have positive effect on POS ( $p<.001)$ with explanatory power of 13.3\% (Ji, 2019); (Jiang and Liang, 2019). In the second step, servant leadership was shown to have positive effect on empowerment $(\mathrm{p}<.001)$ with explanatory power of $9.8 \%$. In the third step of the mediation effects 
test, POS was shown to have significant effect on empowerment ( $p<.001)$, indicating a mediating effect. In the third step, servant leadership was statistically significant ( $\mathrm{p}<.05$ ), with the regression coefficient (B) decreasing from .282 to .140, indicating that POS partially mediates the effect of servant leadership on empowerment, supporting H7.

Table 7. Mediating effect of POS on empowerment

\begin{tabular}{cccc}
\hline & Step1 & Step2 & Step3 \\
\cline { 2 - 4 } & POS & EMP & EMP \\
\hline (Constant) & $1.849^{* * *}$ & $2.059^{* * *}$ & $1.271^{* * *}$ \\
\hline SL & $.333^{* * *}$ & $.282^{* * *}$ & $.140^{*}$ \\
\hline POS & & & $.426^{* * *}$ \\
\hline $\mathrm{R}^{2}$ & .133 & .098 & .259 \\
$\mathrm{~F}$ & $23.815^{* * *}$ & $16.784^{* * *}$ & $26.851^{* * *}$ \\
\hline
\end{tabular}

Dependent Variable: Empowerment

Durbin-Watson's d =2.087

${ }^{*} \mathrm{p}<.05,{ }^{* *} \mathrm{p}<.01,{ }^{* * *} \mathrm{p}<.001$

Ref) SL: Servant Leadership, POS: Perceived Organizational Support, EMP: Empowerment

The mediating effect of POS on the relationship between servant leadership and use of collective intelligence was analyzed and the results are shown in Table 8. In the first step of mediating effect test, the servant leadership was shown to have positive effect on POS ( $\mathrm{p}<.001)$ with explanatory power of $13.3 \%$. In the second step, servant leadership was shown to have positive effect on use of collective intelligence $(\mathrm{p}<.001)$ with explanatory power of $15.0 \%$. In the third step of the mediation effects test, POS was shown to have significant effect on use of collective intelligence ( $\mathrm{p}<.001)$, indicating a mediating effect. In the third step, servant leadership was statistically significant ( $\mathrm{p}<.001$ ), with the regression coefficient (B) decreasing from .274 to .206 , indicating that POS partially mediates the effect of servant leadership on use of collective intelligence, supporting H8.

Table 8. Mediating effect of POS on use of collective intelligence

\begin{tabular}{cccc}
\hline & Step1 & Step2 & Step3 \\
\cline { 2 - 4 } & POS & UCI & UCI \\
\hline (Constant) & $1.849^{* * *}$ & $2.781^{* * *}$ & $2.401^{* * *}$ \\
\hline SL & $.333^{* * *}$ & $.274^{* * *}$ & $.206^{* * *}$ \\
\hline POS & & & $.205^{* *}$ \\
\hline $\mathrm{R}^{2}$ & .133 & .150 & .211 \\
$\mathrm{~F}$ & $23.815^{* * *}$ & $27.407 * * *$ & $20.591^{* * *}$ \\
\hline
\end{tabular}

Dependent Variable: Use of Collective Intelligence

Durbin-Watson's d $=1.990$

${ }^{*} \mathrm{p}<.05,{ }^{* *} \mathrm{p}<.01,{ }^{* * *} \mathrm{p}<.001$

Ref) SL: Servant Leadership, POS: Perceived Organizational Support, UCI: Use of Collective Intelligence

The mediating effect of POS on the relationship between servant leadership and continuous learning was analyzed and the results are shown in Table 9. In the first step of mediating effect test, the servant leadership was shown to have positive effect on POS $(\mathrm{p}<.001)$ with explanatory power of $13.3 \%$. In the second step, servant leadership was shown to have positive effect on continuous learning ( $\mathrm{p}<.01)$ with explanatory power of $5.0 \%$. In the third step of the mediation effects test, POS was shown to have significant effect on continuous learning ( $\mathrm{p}<.001)$, indicating a mediating effect. In the third step, servant leadership was not statistically significant ( $p>.05)$, with the regression coefficient (B) decreasing from .197 to .085 , indicating that POS completely mediates the effect of servant leadership on continuous learning, supporting $\mathrm{H}$ 9. 
Table 9. Mediating effect of POS on continuous learning

\begin{tabular}{cccc}
\hline & Step1 & Step2 & Step3 \\
\cline { 2 - 4 } & POS & CL & CL \\
\hline (Constant) & $1.849^{* * *}$ & $2.420^{* * *}$ & $1.797^{* * *}$ \\
\hline SL & $.333^{* * *}$ & $.197^{* *}$ & .085 \\
\hline POS & & & $.337^{* * *}$ \\
\hline $\mathrm{R}^{2}$ & .133 & .050 & .155 \\
$\mathrm{~F}$ & $23.815^{* * *}$ & $8.197^{* *}$ & $14.172^{* * *}$ \\
\hline
\end{tabular}

Dependent Variable: Continuous Learning

Durbin-Watson's d =1.793

${ }^{*} \mathrm{p}<.05,{ }^{* *} \mathrm{p}<.01,{ }^{* * *} \mathrm{p}<.001$

Ref) SL: Servant Leadership, POS: Perceived Organizational Support, CL: Continuous Learning

These results of mediating effect analysis suggested that servant leadership have a direct effect on the characteristics of agile organizational culture, and furthermore stronger effect through POS. The servant leadership, in particular, has been shown to affect continuous learning only through POS, suggesting that, since the executive servant leadership alone is not sufficient to provide a continuous learning culture that is one of the characteristics of an agile organizations, members must be given perception of the full support and rewards provided by organization.

Table 10 summarizes the above hypothesis test results.

Table 10. Hypothesis test results summary

\begin{tabular}{ccc}
\hline H1 & SL $\rightarrow$ EMP & Supported \\
\hline H2 & POS $\rightarrow$ EMP & Supported \\
\hline H3 & SL $\rightarrow$ UCI & Supported \\
\hline H4 & POS $\rightarrow$ UCI & Supported \\
\hline H5 & SL $\rightarrow$ CL & Not Supported \\
\hline H6 & POS $\rightarrow$ CL & Supported \\
\hline H7 & $\mathrm{SL} \rightarrow(\mathrm{POS}) \rightarrow$ EMP & Supported \\
\hline H8 & $\mathrm{SL} \rightarrow(\mathrm{POS}) \rightarrow$ UCI & Supported \\
\hline H9 & TU $\rightarrow($ POS $) \rightarrow$ CMS & Supported \\
\hline
\end{tabular}

Ref) SL: Servant Leadership, POS: Perceived Organizational Support, EMP: Empowerment,

CL: Continuous Learning, UCI: Use of Collective Intelligence, EV: Eigen Value,

V\%: Variance\%, AV\%: Accumulation Variance\%, CM: Communality,

$\mathrm{C} \alpha-\mathrm{D}$ : Cronbach' $\alpha$ if item is deleted, $\mathrm{C} \alpha$ : Cronbach' $\alpha$

\section{Conclusion}

\subsection{Study Results and Implications}

This study empirically tested the effect of servant leadership and perceived organizational support (POS) on the characteristics of agile organizational culture. The results showed that the servant leadership, an independent variable, has a positive effect on the empowerment and use of collective intelligence among characteristics of agile organizational culture, however, not on continuous learning. The hypothesis that the servant leadership has significant effect on continuous learning, which was developed based on the commitment to growth and developing people, as characteristics of servant leadership, was rejected. This may be due to various factors such as the nature of the sample, necessitating further research in the future. The perceived organizational support (POS) has statistically 
positive effect on all three variables of the characteristics of agile organizational culture: empowerment, use of collective intelligence, and continuous learning. Therefore, it can be seen that POS is an important variable that directly affects agile organizational culture along with servant leadership. The results of test of mediating effect of the POS showed that the POS mediates all the effects of servant leadership on the empowerment, use of collective intelligence, and continuous learning which are characteristics of agile organizational culture. POS, in particular, was shown to completely mediate the relationship between servant leadership and continuous learning. These results indicate that servant leadership plays an important role in establishing the characteristics of agile organizational culture in an organization and that, because the POS mediates this relationship, the characteristics of agile organizational culture may be established more firmly when the organization continues to signal the members with the perception of sufficient support and recognition provided by organization.

\subsection{Limitations and Future Research Directions}

This study was conducted for employees working at headquarters of a specific organization therefore it is difficult to generalize the results to overall industries and organizations. In the future, it is necessary to conduct comparative studies between groups that have introduced agile organizational culture and ones that does not. It is also recommended to conduct additional research and theorize the relationship among various leadership types, factors of organizational support, and characteristics of agile organizational culture.

\section{Acknowledgment}

This research was financially supported by Hansung University.

\section{References}

An, N., Choi, S. H., \& Kang, H. K. (2019). The effects of perceived agile culture of chinese enterprises on job performance: Focused on moderating effect of individual capability. Journal of Digital Convergence, 17(3), 169-180.

Cho, M. H. (2017). An empirical study on effects of IT resources of the firms adopting smart-work on job performance: Focused on mediating effect of collective intelligence and moderating effect of perceived usefulness [dissertation]. [Cheonan (Korea)]. Hoseo University. http://hoseo.dcollection.net/public_resource/pdf/200000004363_20200228161937.pdf

Choi, J. S. (2017). A study on the improvement of organizational effectiveness through the relationship analysis between SNS utilization feature and leadership types on CEOs of SME [dissertation]. [Seoul (Korea)]: Konkuk University. $\quad$ Retrieved http://konkuk.dcollection.net/public_resource/pdf/000002315198_20200225013927.pdf/

Dierendonck, D. V. (2011). Servant Leadership: A Review and Synthesis. Journal of Management, 37, 1228-1261.

Eisenberger, R., \& Peter, F. (1990). Valerie Davis-LaMastro. Perceived organizational support and employee diligence, commitment, and innovation. Journal of Applied Psychology, 75, 1-51.

Greenleaf, R. K. (1970). The servant as leader. Indiana: The Robert K. Greenleaf Center in Indianapolis. Indiana USA.

Gren, L., Torkar, R., \& Feldt, R. (2015). The prospects of a quantitative measurement of agility: A validation study on an agile maturity model. Journal of Systems and Software, 107, 38-49.

Harraf, A. (2015). Organizational agility. Journal of Applied Business Research, 31(2), 675.

Hung, D. M., \& Trinh, B. (2019). Forestry sector and policies on sustainable development in Vietnam: Analyze from the input-output model. International Journal of Social and Administrative Sciences, 4(2), 253-266.

Irshad, M. S. (2017). SWOT analysis of Pakistan-China free trade agreement: Pros and Cons. International Journal of Asian Social Science, 7(1), 45-53.

Jeong, J. J., \& Lee, J. G. (2017). The influences perceived organizational support on level of the learning organization: Mediating effects of affective organizational commitment. The Korean Journal of Human Resource Development Quarterly, 19(2), 109-131. https://doi.org/10.18211/kjhrdq.2017.19.2.005

Jeong, J. S. (2019). Agile Company: five principles to be agile to change. Seoul: Cloud Nine Press.

$\mathrm{Ji}, \mathrm{X}$. (2019). Study on the effect of foreign investment on Anhuis industrial structure optimization. International Journal of Public Policy and Administration Research, 6(2), 82-90.

Jiang, H., \& Liang, T. (2019). Investigate airport service quality-a case study of airports in Shanghai. International 
Journal of Business, Economics and Management, 6(2), 61-75.

Jin, Y. H., \& Kim, S. J. (2016). Effects of authentic leadership and perceived organizational support on organizational citizenship behavior. The Korea Contents Society, 16(4), 23-35.

Kim, H. C. (2015). The impact of enterprises' smart work quality on job satisfaction and work performance: Focusing on mediating effect of collective intelligence [dissertation]. [Seoul (Korea)]. Dongguk University. Retrieved from http://dcollection.dgu.ac.kr/public_resource/pdf/000000067573_20200228155739.pdf

Kim, H. J. (2019). Empirical study of social worker's self-leadership on empowerment, self-efficiency and job satisfaction [dissertation]. [Dangjin (Korea)]. Sehan University. Retrieved from http://daebul.dcollection.net/public_resource/pdf/200000200493_20200228154844.pdf

Kim, T. W. (2018). The effects of authentic leadership on psychological well-being: the mediating effect of LMX and the moderating effect of positive psychological capital [dissertation]. [Seoul (Korea)]. Kyonggi University. Retrieved from http://dcollection.kyonggi.ac.kr/public_resource/pdf/000000052747_20200225021114.pdf

Kim, Y. G. (2019). A study of empathy and perspective-taking on empowerment in adolescents: repeated measure mediated and moderated effects of transformative leadership [dissertation]. [Seoul (Korea)]. Kyonggi University. Retrieved from http://dcollection.kyonggi.ac.kr/public_resource/pdf/000000054523_20200228161122.pdf

Lee, S. Y. (2019). Leadership types, organizational commitment, organizational citizenship behavior, personal performance, collective performance [dissertation]. [Seoul (Korea)]: Kyung Hee University. Retrieved from http://khu.dcollection.net/public_resource/pdf/200000217209_20200225014300.pdf/

Organ, D. W., \& Organ, D. (1990). The motivational basis of organizational citizenship behavior. Res Organizational Behav.

Park, B. M. (2019). A study on the influence of authentic leadership for employee job satisfaction, organizational commitment in the hotel business [dissertation]. [Yangsan (Korea)]. Yeongsan University. Retrieved from http://ysu.dcollection.net/public_resource/pdf/200000224178_20200228153701.pdf

Park, B. W. (2017). Effects of authentic leadership and leader-member exchange on employee creativity in food service industry: The moderating roles of proactive personality and perceived organizational support [dissertation]. [Seoul (Korea)]: Catholic Kwandong University. Retrieved from http://cku.dcollection.net/public_resource/pdf/000002318586_20200225013313.pdf/

Rhoades, L., \& Eisenberger, R. (2002). Perceived organizational support: A review of the literature. Journal of Applied Psychology, 87(4), 698.

Siakas, K. V., \& Siakas, E. (2007). The agile professional culture: A source of agile quality. Software Process: Improvement and Practice, 12(6), 597-610.

Song, S. J. (2018). The structural relationship among social network capital, job autonomy, continuous learning activity, job self-efficacy, and career adaptability of office workers in public institutions [dissertation]. [Seoul $\begin{array}{lllll}\text { (Korea)]. } & \text { Seoul } & \text { National } & \text { University. }\end{array}$ http://dcollection.snu.ac.kr/ezpdfdrm/dCollection.jsp?sItemId=000000149790

Spears, L. C. (1995). Reflections on leadership: How Robert K. Greenleaf's theory of servant-leadership influenced today's top management thinkers. No. 658.4092 R333r. Wiley.

Yu, J. G. (2019). A study on the influence of transformational leadership and servant leadership on organizational citizenship behavior [dissertation]. [Andong (Korea)]. Andong National University. Retrieved from http://andong.dcollection.net/public_resource/pdf/200000218133_20200228152902.pdf 